\title{
Increase in DNA methylation in patients with amyotrophic lateral sclerosis carriers of not fully penetrant SOD1 mutations
}

Fabio Coppedè ${ }^{1, *}$, Andrea Stoccoro ${ }^{1,2}$, Lorena Mosca ${ }^{3}$, Roberta Gallo ${ }^{1}$, Claudia Tarlarini ${ }^{3}$, Christian Lunetta ${ }^{4}$, Alessandro Marocchi $^{3}$, Lucia Migliore ${ }^{1}$, Silvana Penco ${ }^{3, \sharp}$

1) Department of Translational Research and New Technologies in Medicine and Surgery, Section of Medical Genetics, University of Pisa, Via Roma 55, 56126 Pisa, Italy

2) Doctoral School in Genetics Oncology and Clinical Medicine, Department of Medical Biotechnologies, University of Siena, Siena, Italy

3) Medical Genetics Unit, Department of Laboratory Medicine, ASST Grande Ospedale Metropolitano Niguarda, Milan, Italy

4) NEuroMuscular Omnicentre (NEMO), ASST Grande Ospedale Metropolitano Niguarda, Milan, Italy

* This manuscript is dedicated to the memory of Dr. Silvana Penco, who passed away on April $13^{\text {th }}$, 2017. She largely inspired this research, contributed to the manuscript and approved its submission to her last days. We are particularly grateful to her.

*Address for correspondence:

Prof. Fabio Coppedè, Ph.D.

Department of Translational Research

and New Technologies in Medicine and Surgery,

Medical Genetics Lab.

University of Pisa,

Medical School,

Via Roma 55,

56126 Pisa

Phone 0502218544

E-mail: fabio.coppede@med.unipi.it 


\begin{abstract}
Objective: More than 180 different superoxide dismutase 1 (SOD1) mutations have been described so far in amyotrophic lateral sclerosis (ALS) patients, including not completely penetrant ones leading to phenotypic heterogeneity among carriers. We collected DNA samples from five ALS families with not fully penetrant SOD1 mutations (p.Asn65Ser, p.Gly72Ser, p.Gly93Asp, and p.Gly130_Glu133del) searching for epigenetic differences among ALS patients, asymptomatic/paucisymptomatic carriers and non-carrier family members.

Methods: Global DNA methylation levels (5-methylcytosine levels) were determined in blood DNA samples with an enzyme-linked immunosorbent assay (ELISA), and the methylation analysis of SOD1, FUS, TARDBP and C9orf72 genes was performed using Methylation-Sensitive Highresolution melting (MS-HRM) technique.

Results: Global DNA methylation levels were significantly higher in blood DNA of ALS patients than in asymptomatic/paucisymptomatic carriers or family members non-carriers of SOD1 mutations, and a positive correlation between global DNA methylation levels and disease duration (months) was observed. SOD1, FUS, TARDBP and C9orf72 gene promoters were demethylated in all subjects.
\end{abstract}

Conclusions: The present study suggests that global changes in DNA methylation might contribute to the ALS phenotype in carriers of not fully penetrant SOD1 mutations, thus underlying the role of epigenetic factors in modulating the phenotypic expression of the disease.

Keywords: Amyotrophic lateral sclerosis; ALS; superoxide dismutase 1; SOD1; DNA methylation; epigenetics. 


\section{Introduction}

Amyotrophic lateral sclerosis (ALS) results from the degeneration of motor neurons in the motor cortex, brainstem and spinal cord, leading to progressive weakness and atrophy of voluntary skeletal muscles. The average age at onset is between 50 and 60 years, with a similar worldwide incidence of about 1-3 new cases per 100.000 individuals every year. Unfortunately there is no cure for ALS and treatments, which are based on drugs such as Riluzole, only slow the progression of the symptoms, but most of the patients die within 2-3 years of onset, due to respiratory failure (1, 2).

ALS is mainly sporadic (sALS), and only $5-10 \%$ of the cases are inherited (familial ALS = fALS). Four major genes account for most of fALS and for a small percentage of the sporadic cases, namely SOD1 (accounting for $12 \%$ of fALS and about $1 \%$ of sALS cases), TARDBP (5\% of fALS and less than $1 \%$ of sALS), FUS (4\% of fALS and less than $1 \%$ of sALS) and C9orf72 (40\% of fALS and about 7\% of sALS). A few other genes play a significant role in inherited ALS forms, each accounting for less than $1 \%$ of the cases $(2,3)$. In addition to these highly penetrant genes, genome-wide screening has identified more than 100 low penetrance ALS loci, suggesting a polygenic inheritance model and a strong contribution of environmental factors in sALS $(2,3)$. Indeed, risk of ALS may be modulated by environmental factors, gender and ageing, which could be linked to epigenetic events, i.e. changes in gene expression not resulting from changes in the DNA sequence $(4,5)$. In this regard, increasing evidence suggests that epigenetic modifications such as DNA methylation and histone tail modifications might contribute to ALS pathogenesis, and global changes in DNA methylation have been reported in blood and spinal cord DNA of ALS patients, as well as in monozygotic twins discordant for the disease, often leading to altered expression of dozens of genes $(6,7,8)$.

Superoxide dismutase 1 has been the first identified causative ALS gene, and more than 180 different SOD1 mutations have been described so far in ALS patients (9), including not completely 
penetrant and/or paucisymptomatic ones $(10,11,12,13,14,15)$. This last group includes certain SOD1 mutations that may present different clinical courses, even within the same family members, suggesting that additional genetic, environmental or epigenetic factors might contribute to the clinical phenotype $(10,11,12,13,14,15)$. In this regard, a few years ago we described an Italian family with a p.Gly93Asp (G93D) SOD1 gene mutation characterized by a wide variability of disease expression among family members and with the proband showing a fast progressing motor neuron disease compared to the G93D carriers within her family or to previously described cases with the same mutation $(15,16)$. Collectively, the available literature describes slowly progressive cases, asymptomatic carriers, as well as rapidly progressive patients among individuals heterozygous for the G93D SOD1 gene mutation $(14,15,16,17)$. Similar heterozygous SOD1 mutations have been described, including the p.Gly72Ser (G72S) one, resulting in incomplete penetrance and phenotypic variability in the described families $(13,18)$, and the p.Asn65Ser (N65S) mutation which has been described in a few families with reduced penetrance and with a very slow progression of the symptoms in affected individuals $(11,19)$.

In order to evaluate whether or not epigenetic modifications could partially contribute to the phenotypic heterogeneity reported in some carriers of SOD1 mutations we collected 17 DNA samples from two families with the SOD1 G93D missense mutations, and 18 DNA samples from three additional families with other not completely penetrant SOD1 mutations, including G72S, N65S, and a novel SOD1 gene variant p.Gly130_Glu133del. All the subjects were screened for additional mutations in major ALS genes (SOD1, TARDBP, FUS and C9orf72). Furthermore we assessed global DNA methylation levels as well as gene promoter methylation of SOD1, TARDBP, FUS and C9orf72 genes searching for differences among ALS patients, their familial asymptomatic or paucisymptomatic carriers, or non-carriers of SOD1 mutations. 


\section{Materials and Methods}

\section{Subjects and genetic screening}

Blood and DNA samples have been collected from 35 members of five Italian families, including six ALS cases and thirteen asymptomatic/paucisymptomatic carriers of SOD1 mutations as well as sixteen non-carriers of the mutant alleles (Table 1). All included patients fulfilled the El Escorial criteria (20) for probable or definite sporadic ALS and have been diagnosed by neurologists with expertise in ALS. All the study participants were offered genetic test and counselling, and all signed the informed consent approved by the Ethics Committee of the Niguarda Hospital (ASST Grande Ospedale Metropolitano Niguarda, Milan, Italy). Genomic DNA was extracted from whole blood samples using standard procedures (21). Blood and DNA samples have been conserved and are available upon request for further studies, according to the signed informed consent. The search of SOD1, TARDBP, FUS and C9orf72 gene mutations was performed as previously described elsewhere (22-24), and details are available as Supplementary Material.

\section{Families' Description}

The pedigree of each of the five SOD1 families is shown in Figures 1-5. For each family, a summary of the subjects that decided to perform blood drawing for genetic analysis, including details on their age at sampling, is provided in Table 1. Further details on each family are provided (Supplementary Material).

\section{$\rightarrow$ Table 1}




\section{Global DNA methylation analysis}

Quantitative analysis of global 5-methylcytosine (5-mC) levels was determined with the MethylFlash $^{\mathrm{TM}}$ Methylated DNA Quantification Kit (colorimetric) according to the manufacturer's instructions (Epigentek Group Inc., New York, NY, USA). This method is an enzyme-linked immunosorbent assay (ELISA) able to evaluate global degree of DNA methylation. $100 \mathrm{ng}$ of sample DNA and negative and positive controls (unmethylated and methylated control DNA provided by the Epigentek) were incubated in strip wells with a specially developed solution to promote DNA binding and adherence to the well. Wells were treated with 5-mC capture and detection antibodies to measure the methylated fraction of DNA, which was quantified colorimetrically by absorbance readings using a Bio-Rad680 microplate reader (Bio-Rad, Milan, Italy). Standard optical density (OD) values were used to create a standard curve, which provides a slope value, and to determine 5-mC amounts according to the formula: 5-mC (ng) $=$ (sample OD value - negative control OD value) / slope $\times 2$ (a normalization factor for the positive control which contains $50 \%$ of the $5-\mathrm{mC})$. The $5-\mathrm{mC} \%=5-\mathrm{mC}(\mathrm{ng}) /$ the amount of DNA $\times 100$. Results are presented as the percentage of methylated DNA $(5-\mathrm{mC})$ to total DNA.

\section{Methylation sensitive-high resolution melting (MS-HRM) analysis}

The methylation analysis of SOD1, FUS, TARDBP and C9orf72 has been performed using Methylation-Sensitive High-resolution melting (MS-HRM). 200 ng of DNA from each sample were treated with sodium bisulfite in order to convert all unmethylated cytosines into uracil using the EpiTect Bisulfite Kit (Qiagen, Milan, Italy, Catalog $\mathrm{N}^{\circ}$ 59104), following the manufacturer's instructions. C9orf72, SOD1, FUS and TARDBP promoter and first exon regions were analyzed for the presence of $\mathrm{CpG}$ islands by $\mathrm{CpG}$ plot software (EMBOSS Cpgplot). We developed in-house MS-HRM protocols according to literature criteria (26), using methylation independent primers 
(MIP) designed by us using the software MethPrimer (27). In Table 2 are reported primer sequences and annealing temperatures (Ta) used during MS-HRM analysis, as well as the amplicon lenght, the number of studied $\mathrm{CpG}$ sites, the accession number used to take gene sequences to design the primers, and the nucleotide position of the analyzed amplicon.

The MS-HRM analyses were performed as detailed elsewhere (28), and details are provided as Supplementary Materials. Standard DNA samples with known methylation ratios were included in each assay in order to generate standard curves to be used for the deduction of the methylation ratio of each sample. In order to obtain single methylation percentage values from MS-HRM assays, rather than a range, we applied an interpolation method developed in our laboratory (28).

\section{$\rightarrow$ Table 2}

\section{Statistical analyses}

The percentages of gene specific methylation levels and of the global 5-mC content was expressed as mean \pm standard error of the mean (SEM). Differences in mean MS-HRM data and in mean 5-mC content among groups have been evaluated by means of multifactorial analyses of variance (MANOVA), correcting for age at sampling, gender and batch. Linear regression analysis was performed to search for correlation between DNA methylation levels and the duration of the disease (expressed in months from onset). Statistical analyses were performed with STATGRAPHICS 5.1 plus software package for Windows. 


\section{Results}

\section{Genetic screening}

Genetic screening of SOD1, FUS, TARDBP and C9orf72 genes revealed that no additional mutations in one of these four genes was present in the analyzed subjects except for the main SOD1 mutation that characterized each family (Table 1).

\section{Global DNA methylation analysis}

Fig. 6 shows global DNA methylation data detected in ALS patients and in their family members. Multivariate analysis corrected for age at sampling, gender and batch showed that there is a statistically significant difference in 5-mC content (\%) between ALS patients and their family members $(3.41 \pm 0.42$ vs. $2.29 \pm 0.18 ; P=0.02$; Fig. $6 a)$. The analysis revealed that age at sampling $(P=0.58)$, gender $(P=0.43)$, and batch $(P=0.63)$ had no significant effect on global 5-mC content in our samples. Furthermore, when we considered the three different groups, namely ALS patients, asyptomatic/paucisymptomatic carriers, and non-carriers of SOD1 mutations, we observed that ALS individuals showed a significantly higher mean global 5-mC content (\%) than the asyptomatic/paucisymptomatic carriers $(3.41 \pm 0.42$ vs. $2.35 \pm 0.29 ; P=0.04$; Fig. $6 \mathrm{~b})$ or the noncarriers $(3.41 \pm 0.42$ vs. $2.25 \pm 0.26 ; P=0.03$; Fig. $6 b)$. On the contrary, the mean 5 -mC content was very similar between asyptomatic/paucisymptomatic carriers and non-carriers of SOD1 mutations ( $2.35 \pm 0.29$ vs $2.25 \pm 0.26 ; P=0.80$; Fig. $6 b)$. Interestingly, linear regression analysis in the six ALS patients (Fig. 7) revealed a positive correlation between the mean 5-mC content and disease duration in months $(\mathrm{r}=0.88 ; P=0.01)$. When the analyses were restricted to carriers of the G93D missense mutation we obtained similar results than in the global population (Supplementary 
Material). No such analysis was possible for each of the other mutations as we only had one affected individual from each of them.

\section{Gene-specific methylation analysis}

MS-HRM analysis showed that the four genes investigated were hypomethylated in all subjects (Table 3). For each of the studied genes we performed a multivariate analysis corrected for age at sampling, gender and batch, and no difference in DNA methylation levels was detected among the three groups analyzed.

$\rightarrow$ Table 3 


\section{Discussion}

In the present study we focused on five Italian families that carry not fully penetrant ALSrelated SOD1 mutations, observing that the family members with a diagnosis of ALS show a significantly higher mean 5-mC content in blood DNA (average 3.4\%) than the other family members (average 2.3\%). Furthermore, we observed that global DNA methylation levels increase with disease progression in ALS patients and, more interestingly, that asymptomatic/paucisymptomatic carriers of SOD1 mutations have a similar global DNA methylation level (5-mC content) than non-carriers of SOD1 mutations, but significantly lower than ALS patients, reinforcing previous indications that increased DNA methylation characterizes ALS pathogenesis $(6,8)$. The present study revealed also that the four major ALS genes, namely SOD1, TARDBP, FUS and C9orf72, were demethylated in all the studied individuals, and no additional mutations in those genes were detected, suggesting that the observed increased global 5-mC content in ALS patients is likely to occur in other genes or genomic regions.

In 2014, Tremolizzo and coworkers observed that whole-blood global DNA methylation was increased in ALS subjects independently of age at onset in a cohort composed by 96 ALS patients, mainly sporadic, and 87 controls (8). Figueroa-Romero and coworkers investigated 11 ALS patients and 12 controls observing a significant increase in global DNA methylation (5-mC content) in the spinal cord DNA of ALS patients respect to controls (6). Similarly, studies in cell cultures and animal models of the disease revealed that motor neurons engage epigenetic mechanisms to drive apoptosis, involving up-regulation of DNA methyltransferases (DNMTs) and increased global DNA methylation (29). More recently, a report of two monozygotic twins of Italian descent who were ALS-discordant for 17 years, and heterozygous for the p.Thr137Ala (T137A) SOD1 mutation, revealed that the unaffected twin had a younger DNA methylation age than the affected one, suggesting a contribution played by environmental factors in the affected one (30). The present study, which is the first collecting samples from different ALS families that carry not fully 
penetrant SOD1 mutations, confirms increased global DNA methylation (5-mC levels) in ALS blood DNA respect to asymptomatic/paucisymptomatic carriers or to non-carriers of SOD1 mutations, strengthening previous evidence of an epigenetic involvement in ALS pathogenesis/clinical course. We must however acknowledge the fact that one-half of the subjects collected for the study are from SOD1 G93D families that included several asymptomatic carriers of comparable age with the patients, so that data are quite convincing in those families (Supplementary Material). In the other families we only have one ALS case for each given mutation, so that data cannot be related to each single mutation, but must be taken collectively.

While the alteration of DNA methylation has recently been reported in ALS, the involvement of multiple epigenetic players and the environmental contribution to the observed epigenetic changes still needs to be clarified (4). The methylation status of SODI and $V E G F$ gene promoters was determined in white cell DNA of 10 ALS patients and in brain DNA of six of them, and both genes resulted largely hypomethylated in both tissues (31). Consistently with that study, the present investigation of SOD1 methylation revealed that the gene was largely hypomethylated in our samples. Many investigators reported increased C9orf72 methylation in ALS or frontotemporal dementia patients with a C9orf72 repeat expansion, but not in healthy controls or in those with normal short repeats $(32,33)$. In the present study no ALS patient had a C9orf72 repeat expansion, and no subject showed methylation of the C9orf72 gene. Also FUS and TARDBP genes resulted hypomethylated in our samples but, at best of our knowledge, little is known about their methylation levels in ALS tissues so far.

For what is concerning environmental factors, early-life events, metal exposure, and the patients' work and lifestyle have been suggested to contribute to epigenetic changes in ALS, but evidence is inconclusive to make any definitive conclusion $(34,35,36)$. In this regard, recent genome-wide expression studies suggest that genes involved in inflammation and or immune response are deregulated in ALS tissues, likely representing potential targets of environmentally induced epigenetic modifications $(6,7)$. Unfortunately, we do not have RNA samples from our 
patients to search for gene-expression levels and further address this issue. Collectively, both global and gene-specific methylation changes have been observed in affected neurons and in blood DNA samples of individuals affected by complex neurodegenerative disorders, such as ALS, Alzheimer's disease (AD) or Parkinson's disease (PD), and it is still largely debated if the observed changes are cause or consequence of the disease $(8,37,38)$. For example, early-life exposure to metals or dietary restrictions have been suggested to contribute to epigenetic changes resulting in increased risk to develop AD-related symptoms later in life in animal models (39), but there is also evidence that toxic molecules produced within disease progression, such as the amyloid beta peptide, could contribute to the observed changes in DNA methylation (40). For what is concerning ALS, the global changes in DNA methylation levels observed in monozygotic twins discordant for the disease suggest that lifelong environmental exposures could have contributed to the onset of the disease in the affected twins $(7,30)$, at the same time there is evidence suggesting that global changes in DNA methylation could contribute to disease progression (29), and the present study revealed an increase in blood DNA methylation levels with the duration of the disease. However, despite that epigenetic changes could either contribute to the neurodegenerative process or increase as a consequence of the disease itself, they are reversible in nature and offer a potential target for therapeutic interventions (41), and in this regard studies in ALS cell cultures and animal models have provided evidence of a beneficial effect exerted by DNMT inhibitors $(29,42)$.

Overall, the present study suggests that global changes in DNA methylation might contribute to the ALS phenotype in carriers of not fully penetrant SOD1 mutations, and those changes seem to increase with disease progression. We are aware that the number of families included in the study is relatively small, so that confirmation in additional clusters is required as gathering together samples from different families could help to identify the targets of the epigenetic changes, although very informative ALS families such as those here described are not so frequent. Indeed, the strength of the study is the availability of families carrying peculiar SOD1 mutations that allowed having 13 asymptomatic/paucisymptomatic carriers without a diagnosis of ALS as well as some patients with 
slowly progressive ALS forms. The analysis of the asymptomatic carriers revealed that the presence of the studied SOD1 mutations alone is not sufficient to increase the global 5-mC content, whilst the occurrence of certain ALS patients with either p.Asn65Ser or p.Gly93Asp mutations and a very slow disease progression suggested that global DNA methylation levels increase with the duration of the disease, a data that if confirmed in other ALS families could open the way for therapeutic opportunities. In addition, present data suggest a possible link between environmental factors and epigenetic modifications as modulators of the ALS phenotype in genetically determined FALS forms. Despite that it is always difficult to evaluate early-life or lifelong environmental exposures in adults, studies in cell cultures, animal models, or twins discordant for neurodegenerative disorders, have suggested that factors such as metals, pesticides, head injuries, psychological stress, smoking and dietary factors can epigenetically modulate the expression of disease-related genes (33-39), so that we could postulate that changes in lifestyle may possibly prevent or slow down the phenotypic expression of the disease.

\section{Acknowledgements}

This swork was supported by a grant from "ASSOCIAZIONE IO CORRO CON GIOVANNI", www.iocorrocongiovanni.org; info@iocorrocongiovanni.org; Paina di Giussano - Via IV Novembre 20 - c/o Centro Associativo "Generazioni".

\section{Declaration of interest statement}

The authors declare that they have no competing interests. 


\section{References}

1. Al-Chalabi A, Hardiman O, Kiernan MC, Chiò A, Rix-Brooks B, van den Berg, LH. Amyotrophic lateral sclerosis: moving towards a new classification system. Lancet Neurol. 2016;15:1182-94.

2. Ji AL, Zhang X, Chen WW, Huang WJ. Genetics insight into the amyotrophic lateral sclerosis/frontotemporal dementia spectrum. J Med Genet 2017;pii:jmedgenet-2016-104271.

3. van Rheenen W, Shatunov A, Dekker AM, McLaughlin RL, Diekstra FP, Pulit, SL, et al. Genome-wide association analyses identify new risk variants and the genetic architecture of amyotrophic lateral sclerosis. Nat Genet. 2016;48:1043-8.

4. Belzil VV, Katzman RB, Petrucelli L. ALS and FTD: an epigenetic perspective. Acta Neuropathol. 2016;132:487-502.

5. Paez-Colasante X, Figueroa-Romero C, Sakowski SA, Goutman SA, Feldman EL. Amyotrophic lateral sclerosis: mechanisms and therapeutics in the epigenomic era. Nat Rev Neurol. 2015;11:26679.

6. Figueroa-Romero C, Hur J, Bender DE, Delaney CE, Cataldo MD, Smith AL, et al. Identification of epigenetically altered genes in sporadic amyotrophic lateral sclerosis. PLoS One. 2012;7:e52672.

7. Lam L, Chin L, Halder RC, Sagong B, Famenini S, Sayre J, et al. Epigenetic changes in T-cell and monocyte signatures and production of neurotoxic cytokines in ALS patients. FASEB J. 2016;30:3461-3473. 
8. Tremolizzo L, Messina P, Conti E, Sala G, Cecchi M, Airoldi L, et al. Whole-blood global DNA methylation is increased in amyotrophic lateral sclerosis independently of age of onset. Amyotroph Lateral Scler Frontotemporal Degener. 2014;15:98-105.

9. Gene report of major ALS genes in ALSoD. http://alsod.iop.kcl.ac.uk/. Accessed 09 May 2017.

10. Conforti FL, Barone R, Fermo SL, Giliberto C, Patti F, Gambardella A, et al. Sporadic motor neuron disease in a familial novel SOD1 mutation: incomplete penetrance or chance association? Amyotroph Lateral Scler. 2011;12:220-2.

11. Corrado L, D'Alfonso S, Bergamaschi L, Testa L, Leone M, Nasuelli N, et al. SOD1 gene mutations in Italian patients with Sporadic Amyotrophic Lateral Sclerosis (ALS). Neuromuscul Disord. 2006;16:800-4.

12. Kim W, Kim JS, Lee KS, Gwoun YJ, Kim JM, Lee KH. Anticipation and phenotypic heterogeneity in korean familial amyotrophic lateral sclerosis with superoxide dismutase 1 gene mutation. J Clin Neurol. 2007;3:38-44.

13. Kobayashi Z, Tsuchiya K, Kubodera T, Shibata N, Arai T, Miura H, et al. FALS with Gly72Ser mutation in SOD1 gene: report of a family including the first autopsy case. J Neurol Sci. $2011 ; 300: 9-13$.

14. Luigetti M, Madia F, Conte A, Marangi G, Zollino M, Del Grande A, et al. SOD1 G93D mutation presenting as paucisymptomatic amyotrophic lateral sclerosis. Amyotroph Lateral Scler. 2009;10:479-82. 
15. Penco S, Lunetta C, Mosca L, Maestri E, Avemaria F, Tarlarini C, et al. Phenotypic heterogeneity in a SOD1 G93D Italian ALS family: an example of human model to study a complex disease. J Mol Neurosci. 2011;44:25-30.

16. Restagno G, Lombardo F, Sbaiz L, Mari C, Gellera C, Alimonti D, et al. The rare G93D mutation causes a slowly progressing lower motor neuron disease. Amyotroph Lateral Scler. 2008;9:35-9.

17. Luigetti M, Lattante S, Zollino M, Conte A, Marangi G, Del Grande A, Sabatelli M. SOD1 G93D sporadic amyotrophic lateral sclerosis (SALS) patient with rapid progression and concomitant novel ANG variant. Neurobiol Aging. 2011;32:1924.e15-8.

18. Orrell RW, Marklund SL, deBelleroche JS. Familial ALS is associated with mutations in all exons of SOD1: a novel mutation in exon 3 (Gly72Ser). J Neurol Sci. 1997;153:46-9.

19. García-Redondo A, Bustos F, Juan Y Seva B, Del Hoyo P, Jiménez S, Campos Y, et al. Molecular analysis of the superoxide dismutase 1 gene in Spanish patients with sporadic or familial amyotrophic lateral sclerosis. Muscle Nerve. 2002;26:274-8.

20. Brooks BR, Miller RG, Swash M, Munsat TL. El Escorial revisited: revised criteria for the diagnosis of amyotrophic lateral sclerosis. Amyotroph Lateral Scler Other Motor Neuron Disord. 2000;1:293-9.

21. Miller SA, Dykes DD, Polesky HF,. A simple salting out procedure for extracting DNA from human nucleated cells. Nucleic Acids Res. 1988;16:1215. 
22. Millecamps S, Salachas F, Cazeneuve C, Gordon P, Bricka B, Camuzat A, et al. SOD1, ANG, VAPB, TARDBP, and FUS mutations in familial amyotrophic lateral sclerosis: genotypephenotype correlations. J Med Genet. 2010:47,554-60.

23. Renton AE, Majounie E, Waite A, Simón-Sánchez J, Rollinson S, Gibbs JR, et al. A hexanucleotide repeat expansion in C9ORF72 is the cause of chromosome 9p21-linked ALS-FTD. Neuron. 2011;72:257-68.

24. Tarlarini C, Lunetta C, Mosca L, Avemaria F, Riva N, Mantero V, et al. Novel FUS mutations identified through molecular screening in a large cohort of familial and sporadic amyotrophic lateral sclerosis. Eur J Neurol. 2015;22:1474-81.

25. DeJesus-Hernandez M, Mackenzie IR, Boeve BF, Boxer AL, Baker M, Rutherford NJ, et al.. Expanded GGGGCC hexanucleotide repeat in noncoding region of C9ORF72 causes chromosome 9p-linked FTD and ALS. Neuron. 2011;72:245-56.

26. Wojdacz TK, Dobrovic A, Hansen LL. Methylation-sensitive high-resolution melting. Nat Protoc. 2008;3:1903-8.

27. Li LC, Dahiya R. MethPrimer: designing primers for methylation PCRs. Bioinformatics. 2002;18:1427-31.

28. Migheli F, Stoccoro A, Coppedè F, Wan Omar WA, Failli A, Consolini R, et al.. Comparison study of MS-HRM and pyrosequencing techniques for quantification of APC and CDKN2A gene methylation. PLoS One. 2013;8:e52501. 
29. Chestnut BA, Chang Q, Price A, Lesuisse C, Wong M, Martin LJ. Epigenetic regulation of motor neuron cell death through DNA methylation. J Neurosci. 2011;31:16619-36.

30. Zhang M, Xi Z, Ghani M, Jia P, Pal M, Werynska K, Moreno D. Genetic and epigenetic study of ALS-discordant identical twins with double mutations in SOD1 and ARHGEF28. J Neurol Neurosurg Psychiatry. 2016;87:1268-1270.

31. Oates N, Pamphlett R. An epigenetic analysis of SOD1 and VEGF in ALS. Amyotroph Lateral Scler. 2007;8:83-6.

32. Gijselinck I, Van Mossevelde S, van der Zee J, Sieben A, Engelborghs S, De Bleecker J, et al. The C9orf72 repeat size correlates with onset age of disease, DNA methylation and transcriptional downregulation of the promoter. Mol Psychiatry. 2016;21:1112-24.

33. Xi Z, Yunusova Y, van Blitterswijk M, Dib S, Ghani M, Moreno D, et al. Identical twins with the C9orf72 repeat expansion are discordant for ALS. Neurology. 2014;83:1476-8.

34. Callaghan B, Feldman D, Gruis K, Feldman E. The association of exposure to lead, mercury, and selenium and the development of amyotrophic lateral sclerosis and the epigenetic implications. Neurodegener Dis. 2011;8:1-8.

35. Garzillo EM, Miraglia N, Pedata P, Feola D, Lamberti M. Risk agents related to work and amyotrophic lateral sclerosis: An occupational medicine focus. Int J Occup Med Environ Health. 2016;29:355-67. 
36. Rooney J. Further thoughts on mercury, epigenetics, genetics and amyotrophic lateral sclerosis. Neurodegener Dis. 2011;8:523-4.

37. Coppedè F. Genetics and epigenetics of Parkinson's disease. ScientificWorldJournal. 2012;2012:489830.

38. Sanchez-Mut JV, Gräff J. Epigenetic Alterations in Alzheimer's Disease. Front Behav Neurosci. $2015 ; 9: 347$.

39. Lahiri DK, Maloney B, Basha MR, Ge YW, Zawia NH. How and when environmental agents and dietary factors affect the course of Alzheimer's disease: the "LEARn" model (latent early-life associated regulation) may explain the triggering of AD. Curr Alzheimer Res. 2007;4:219-28.

40. Sung HY, Choi BO, Jeong JH, Kong KA, Hwang J, Ahn JH. Amyloid Beta-Mediated Hypomethylation of Heme Oxygenase 1 Correlates with Cognitive Impairment in Alzheimer's Disease. PLoS One. 2016;11:e0153156.

41. Coppedè F. The potential of epigenetic therapies in neurodegenerative diseases. Front Genet. 2014;5:220.

42. Oh YS, Kim SH, Cho GW. Functional Restoration of Amyotrophic Lateral Sclerosis PatientDerived Mesenchymal Stromal Cells Through Inhibition of DNA Methyltransferase. Cell Mol. Neurobiol. 2016;36:613-320. 


\section{Tables}

Table 1. Summary of the main characteristics of subjects included in the study.

\begin{tabular}{|c|c|c|c|c|c|c|c|c|}
\hline Subject $^{1}$ & $\begin{array}{l}\text { Age at } \\
\text { sampling }\end{array}$ & Gender & $\begin{array}{l}\text { Age at } \\
\text { onset }\end{array}$ & $\begin{array}{l}\text { Disease duration } \\
\text { (onset to blood } \\
\text { drawing) }\end{array}$ & $\begin{array}{l}\text { Site of } \\
\text { onset }^{2}\end{array}$ & SOD1 Mutations & $\begin{array}{l}\text { Other } \\
\text { mutations: } \\
\text { TARDBP, } \\
\text { FUS, C9orf72 }\end{array}$ & Notes \\
\hline \multicolumn{9}{|l|}{ Family 1} \\
\hline IV:7 & 34 & $\mathrm{~F}$ & 29 & 60 months & UL & p.Gly93Asp & No & Onset in pregnancy \\
\hline III:2 & 57 & $\mathrm{~F}$ & / & & 1 & p.Gly93Asp & No & \\
\hline III:4 & 54 & $\mathrm{~F}$ & l & & 1 & No & No & \\
\hline III:5 & 45 & $\mathrm{~F}$ & 1 & & 1 & p.Gly93Asp & No & \\
\hline III:8 & 64 & $\mathrm{M}$ & l & & 1 & No & No & \\
\hline III:9 & 58 & $\mathrm{~F}$ & 1 & & 1 & p.Gly93Asp & No & \\
\hline III: 10 & 60 & $\mathrm{~F}$ & 50 & 127 months & $\mathrm{LL}$ & p.Gly93Asp & No & \\
\hline III:12 & 52 & $\mathrm{M}$ & 1 & & 1 & p.Gly93Asp & No & \\
\hline IV:9 & 39 & $\mathrm{M}$ & I & & 1 & No & No & \\
\hline IV:11 & 25 & $\mathrm{M}$ & 1 & & 1 & p.Gly93Asp & No & \\
\hline IV:12 & 24 & $\mathrm{M}$ & 1 & & 1 & p.Gly93Asp & No & \\
\hline IV:13 & 22 & $\mathrm{~F}$ & 1 & & 1 & p.Gly93Asp & No & \\
\hline IV:14 & 20 & $\mathrm{M}$ & I & & 1 & p.Gly93Asp & No & \\
\hline \multicolumn{9}{|l|}{ Family 2} \\
\hline III:1 & 18 & $\mathrm{~F}$ & 18 & 9 months & LL & p.Gly93Asp & No & \\
\hline II:1 & 60 & $\mathrm{M}$ & I & & I & No & No & \\
\hline $\mathrm{II}: 2$ & 48 & $\mathrm{~F}$ & 1 & & 1 & p.Gly93Asp & No & \\
\hline
\end{tabular}




\begin{tabular}{|c|c|c|c|c|c|c|c|c|}
\hline & & & & & & & & Alzheimer's disease \\
\hline III:6 & 49 & $\mathrm{~F}$ & / & & 1 & p.Asn65Ser & No & \\
\hline III:8 & 51 & $\mathrm{~F}$ & / & & 1 & No & $\mathrm{No}$ & \\
\hline \multicolumn{9}{|c|}{ Family 4} \\
\hline III:2 & 40 & $\mathrm{M}$ & 36 & 45 months & LL & p.Gly130_Glu133del & $\mathrm{No}$ & \\
\hline III:3 & 44 & $\mathrm{~F}$ & 1 & & 1 & No & No & \\
\hline III:4 & 42 & $\mathrm{~F}$ & 1 & & 1 & p.Gly130_Glu133del & $\mathrm{No}$ & \\
\hline III:5 & 34 & $\mathrm{~F}$ & / & & 1 & No & No & \\
\hline II:5 & 52 & $\mathrm{~F}$ & / & & 1 & No & No & \\
\hline II:4 & 56 & $\mathrm{M}$ & 1 & & 1 & No & No & \\
\hline II:3 & 58 & $\mathrm{~F}$ & 1 & & 1 & No & No & \\
\hline II:2 & 61 & $\mathrm{M}$ & I & & 1 & No & No & \\
\hline II:1 & 63 & $\mathrm{~F}$ & / & & 1 & No & No & \\
\hline \multicolumn{9}{|c|}{ Family 5} \\
\hline III:2 & 60 & $\mathrm{M}$ & 57 & 38 months & UL & p.Gly72Ser & No & \\
\hline II:2 & 84 & $\mathrm{~F}$ & 1 & & 1 & p.Gly72Ser & No & $\begin{array}{l}\text { Since } 77 \text { years old limbs } \\
\text { deambulation problems. } \\
\text { However, she is still } \\
\text { autonomous, speaks and } \\
\text { moves }\end{array}$ \\
\hline III:4 & 47 & $\mathrm{~F}$ & 1 & & 1 & No & No & \\
\hline IV:1 & 33 & $\mathrm{M}$ & 1 & & 1 & No & No & \\
\hline IV:2 & 30 & $\mathrm{M}$ & 1 & & 1 & p.Gly72Ser & No & \\
\hline
\end{tabular}

${ }^{1}$ Each subject belongs to the described families: For the family trees see figure 1 for family 1 , figure 2 for family 2 , figure 3 for family 3 , figure 4 for family 4, and figure 5 for family 5 .

${ }^{2}$ LL: lower limbs; UP: upper limbs; G: generalized. 
Table 2. Primer sequences, annealing temperatures (Ta) used during MS-HRM analysis, amplicon length, number of CpG sites, accession number and nucleotide position of the regions analyzed for each of the studied genes.

\begin{tabular}{|c|c|c|c|c|c|c|}
\hline Gene & Primer sequence & $\mathbf{T}_{\mathbf{a}}$ & Amplicon lenght & $\begin{array}{l}\text { CpG } \\
\text { sites }\end{array}$ & Accession Number & $\begin{array}{l}\text { Nucleotide } \\
\text { position }\end{array}$ \\
\hline C9orf & $\begin{array}{l}\text { F 5'-TTTTTTTTAGATTTAGTAGTTTTTTTTATT-3', } \\
\text { R 5'- ACAACTTATCCTATTCTTTTATCTTAAAAC-3, }\end{array}$ & $55^{\circ}$ & $102 \mathrm{bp}$ & 5 & NG_031977.1 & Nt. $4842-4943$ \\
\hline SOD1 & $\begin{array}{l}\text { F 5'-GTGTTGTTTTTTGTGGTTTTTG-3' } \\
\text { R 5'- AAAAACCATTCCTAACCTTAAAACTATAC-3' }\end{array}$ & $59^{\circ}$ & $262 \mathrm{bp}$ & 22 & NG_008689.1 & Nt. 5517-5778 \\
\hline FUS & $\begin{array}{l}\text { F 5'-ATTTTTTTTGGTTTTAAGGATGGTT-3, } \\
\text { R 5'- TCTTTCAAAATTACCTTACCTTTC-3' }\end{array}$ & $54^{\circ}$ & $201 \mathrm{bp}$ & 10 & NG_012889.2 & Nt. $4275-4475$ \\
\hline$T A R D B P$ & $\begin{array}{l}\text { F 5'-TTTTATTTTGTTTTTTAGGTGGATT-3', } \\
\text { R 5'- AACTATATAAAAACTAACCTCCCCC-3' }\end{array}$ & $58^{\circ}$ & $209 \mathrm{bp}$ & 22 & NC_000001.11 & Nt. 11012238-446 \\
\hline
\end{tabular}


Table 3. Mean gene methylation levels (\%) obtained with MS-HRM analysis.

\begin{tabular}{|c|c|c|c|c|}
\hline Gene & $\begin{array}{c}\text { ALS patients } \\
(\mathrm{n}=6)(\text { mean } \pm \text { SEM) }\end{array}$ & $\begin{array}{c}\text { Asymptomatic/paucisymptomatic } \\
\text { carriers }(\mathrm{n}=13) \\
(\text { mean } \pm \text { SEM) }\end{array}$ & $\begin{array}{c}\text { Non-carriers } \\
(\mathrm{n}=16) \\
(\text { mean } \pm \text { SEM })\end{array}$ & $P$-value \\
\hline SOD1 & 0.00 & $0.22 \pm 0.15$ & 0.00 & 0.57 \\
\hline FUS & $0.39 \pm 0.18$ & $0.03 \pm 0.10$ & $0.08 \pm 0.11$ & 0.25 \\
\hline TARDBP & 0.00 & $0.05 \pm 0.02$ & $0.02 \pm 0.02$ & 0.33 \\
\hline C9 orf72 & 0.00 & $0.14 \pm 0.05$ & $0.05 \pm 0.07$ & 0.52 \\
\hline
\end{tabular}

${ }^{a}$ Multifactorial analysis of variance adjusted for age at sampling, gender and batch. 


\section{Figure captions}

\section{Figure 1}

Pedigree of the SOD1 p.Gly93Asp ALS family: square, male; circle, female; slash, c symbol, affected; arrow, index patient; horizontal double line, consanguineous marr: patient mutated; wt, wild type.

\section{Figure 2}

Pedigree of family 2 with p.Gly93Asp mutation in the SOD1 gene: square, male; cir solid symbol, affected; arrow, index patient; asterisk, patient mutated; wt, wild type.

\section{Figure 3}

Pedigree of family 3 with p.Asn65Ser mutation in the SOD1 gene. Square indicates female; solid symbol, affected; slash, deceased; small solid circle symbol, abortion; patient; asterisk, patient mutated; wt, wild type. Squares or circle filled with number number of other family members not shown in the pedigree.

\section{Figure 4}

Pedigree of the SOD1 p.(Gly130_Glu133del) ALS family. Square indicates male; ci solid symbol, affected; slash, deceased; arrow, index patient; asterisk, patient mutat $\epsilon$ type.

\section{Figure 5}

Pedigree of family 5 with p.Gly 72 Ser mutation in the SOD1 gene: square, male; circ solid symbol, affected; arrow, index patient; asterisk, patient mutated; wt, wild type: double line, consanguineous marriage; diamond; sex unknown. 


\section{Figure 6}

Global DNA methylation levels (5-mC\%) in ALS patients and in their relatives (A), and in ALS patients, asyptomatic/paucisymptomatic carriers, and non-carriers of $S O D 1$ mutations (B). $P$-value obtained by means of multifactorial analysis of variance adjusted for age at sampling, gender and batch.

\section{Figure 7}

Correlation between global DNA methylation $(5-\mathrm{mC} \%)$ and duration of the disease (months from onset). Linear regression analysis showed a statistically significant correlation between 5-mC\% content and disease duration $(\mathrm{r}=0.88 ; P=0.01)$. 


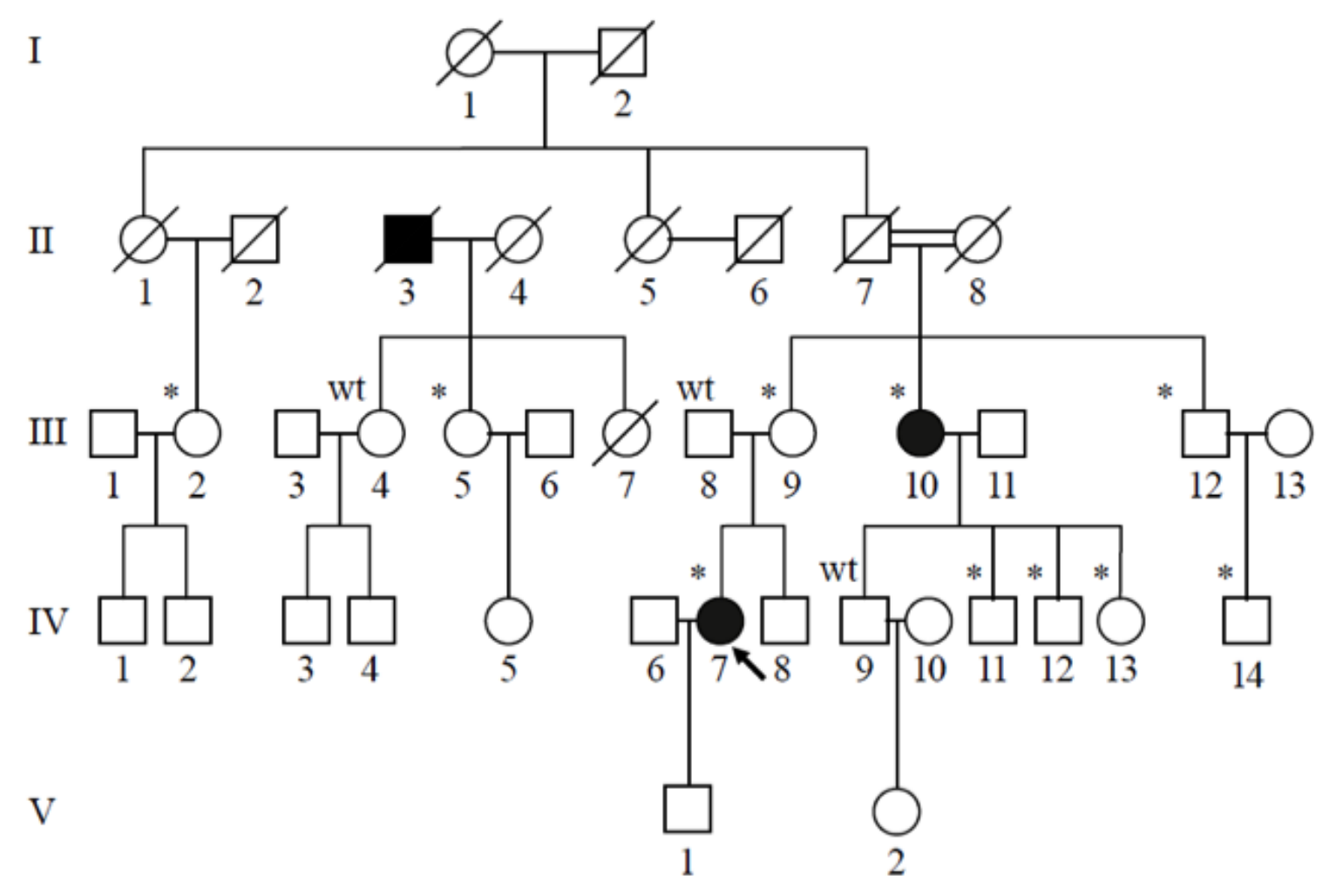

Figure 1 


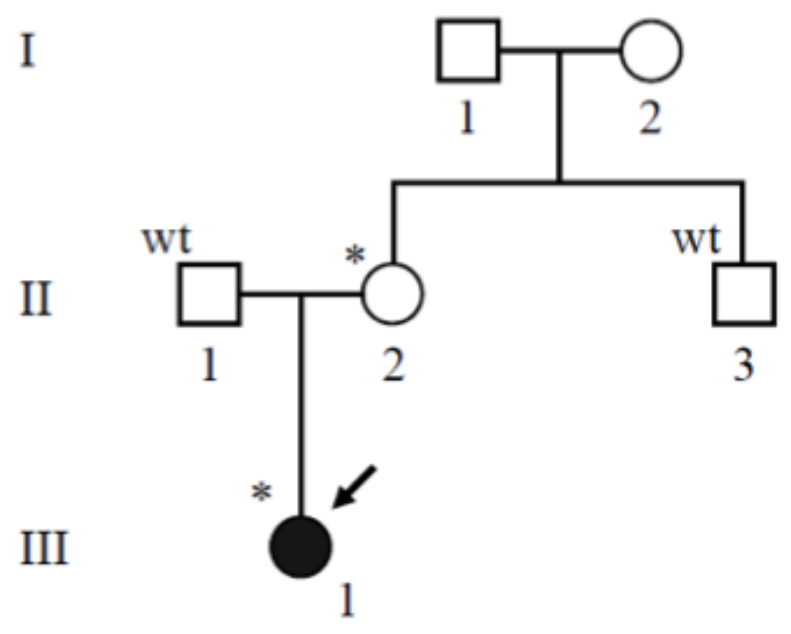

Figure 2 


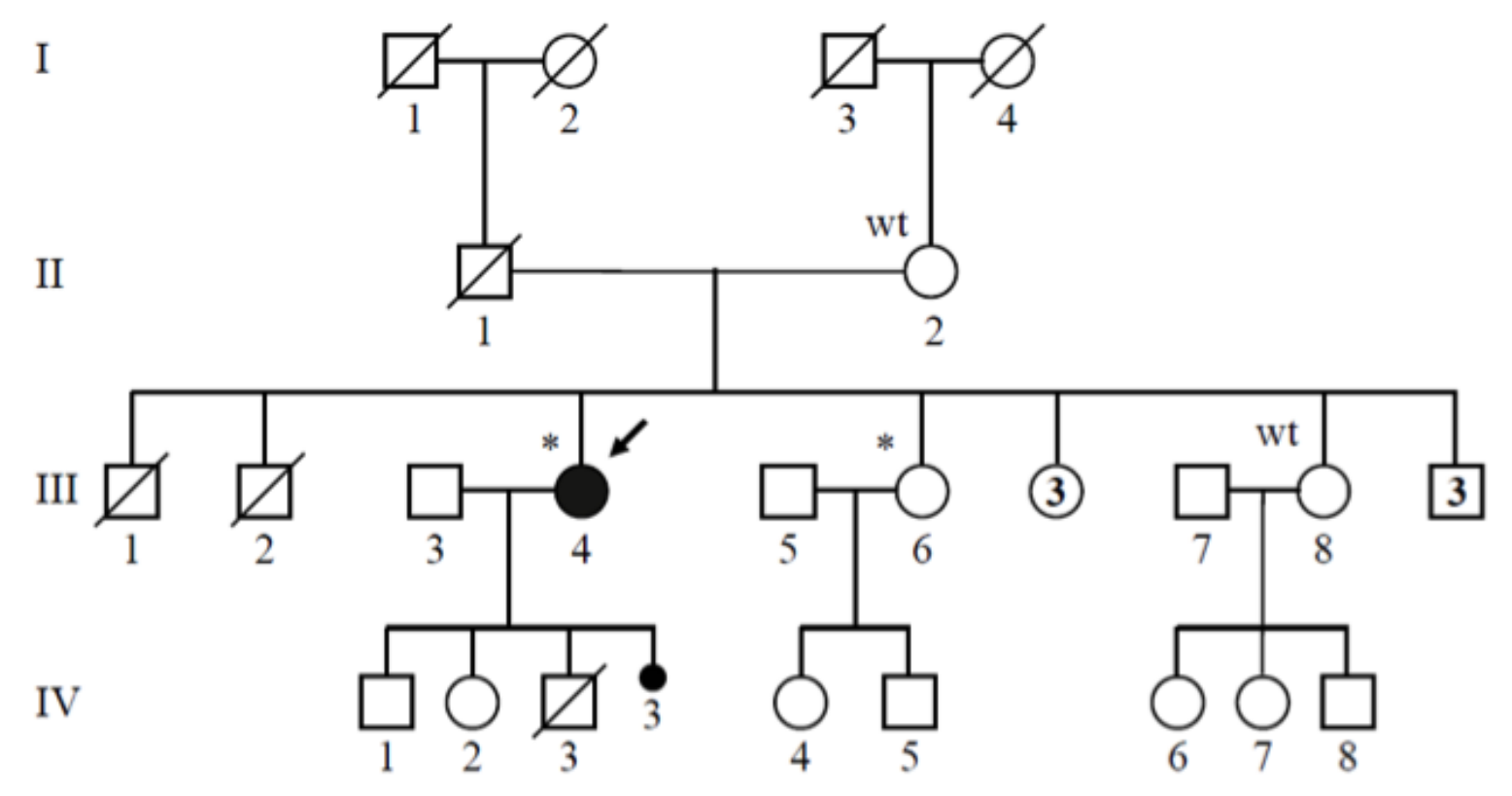

Figure 3 


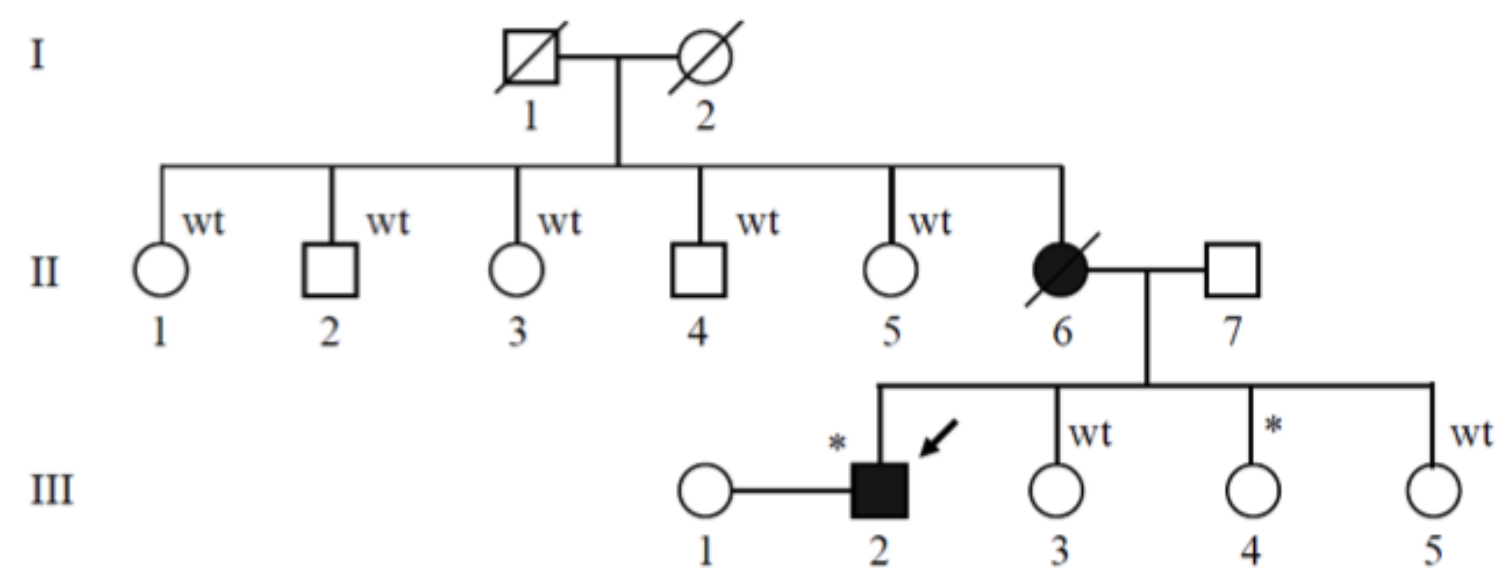

Figure 4 
I

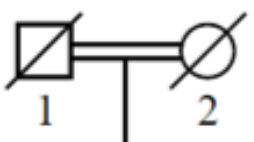

II

1

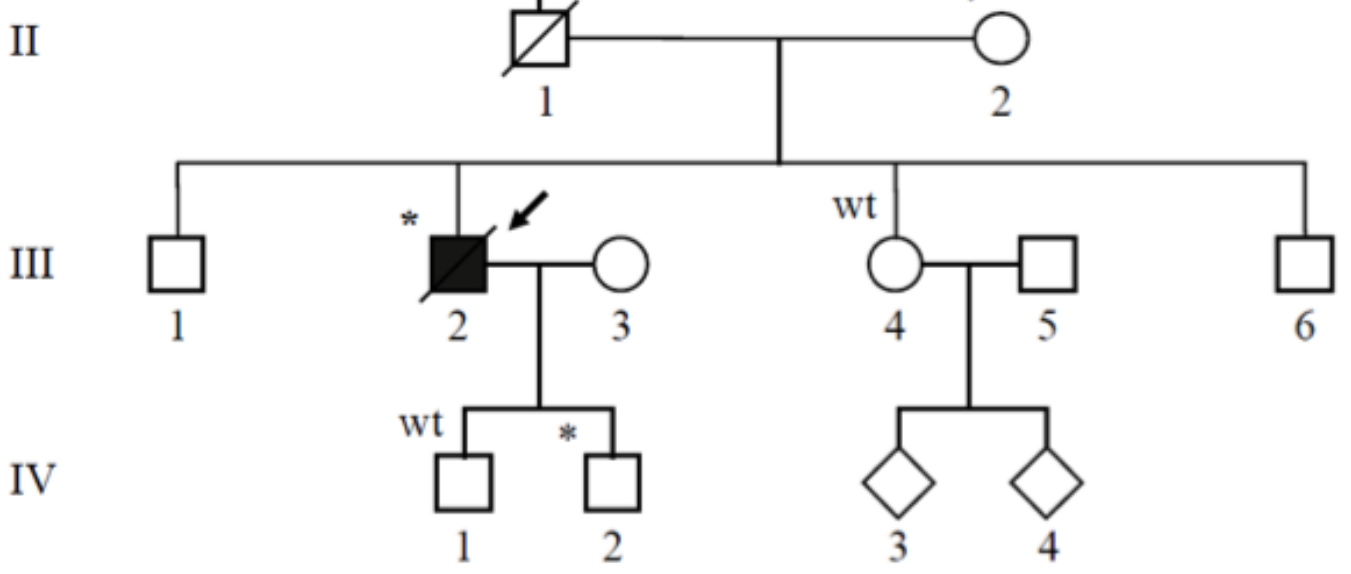

Figure 5 

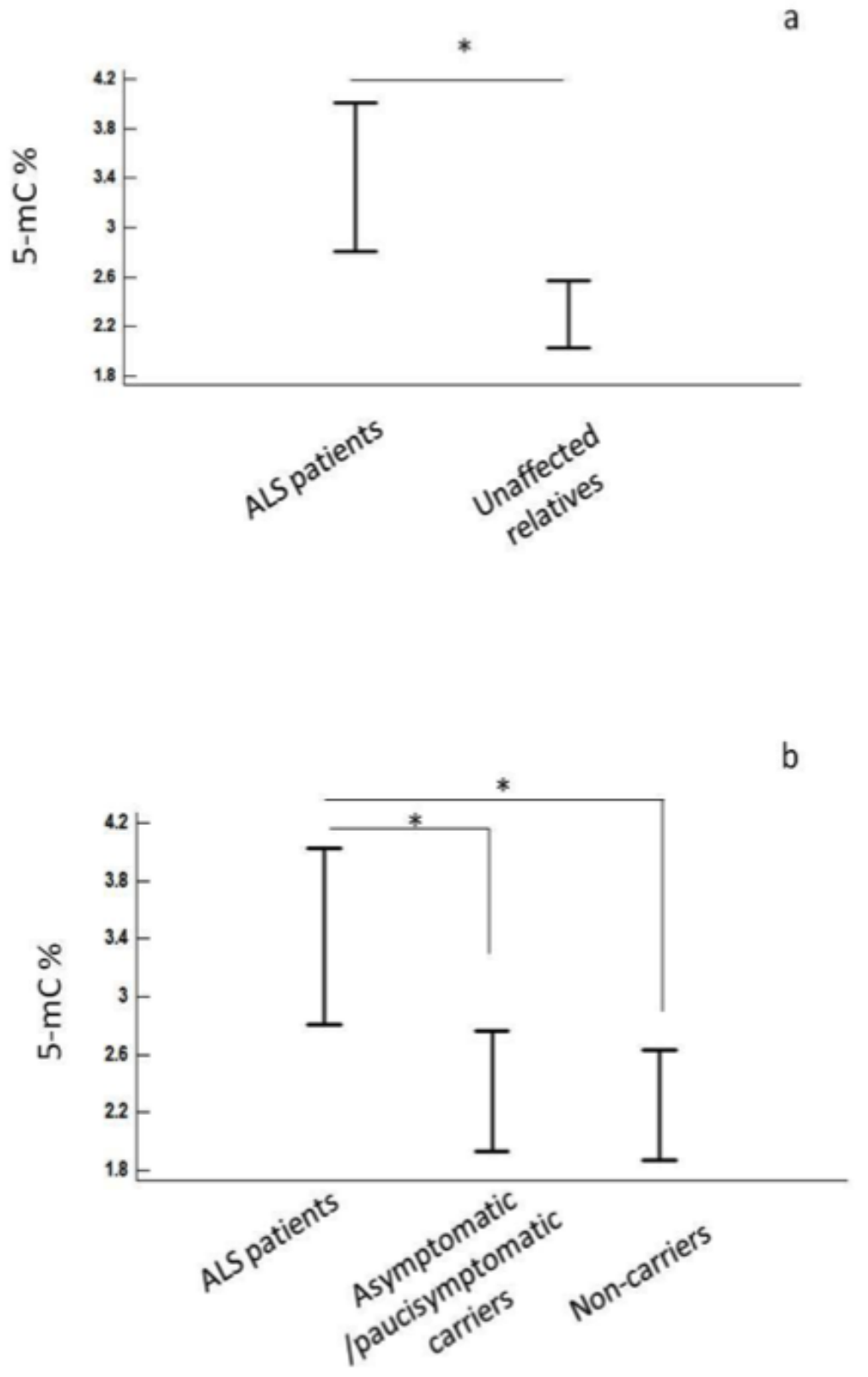

Figure 6 


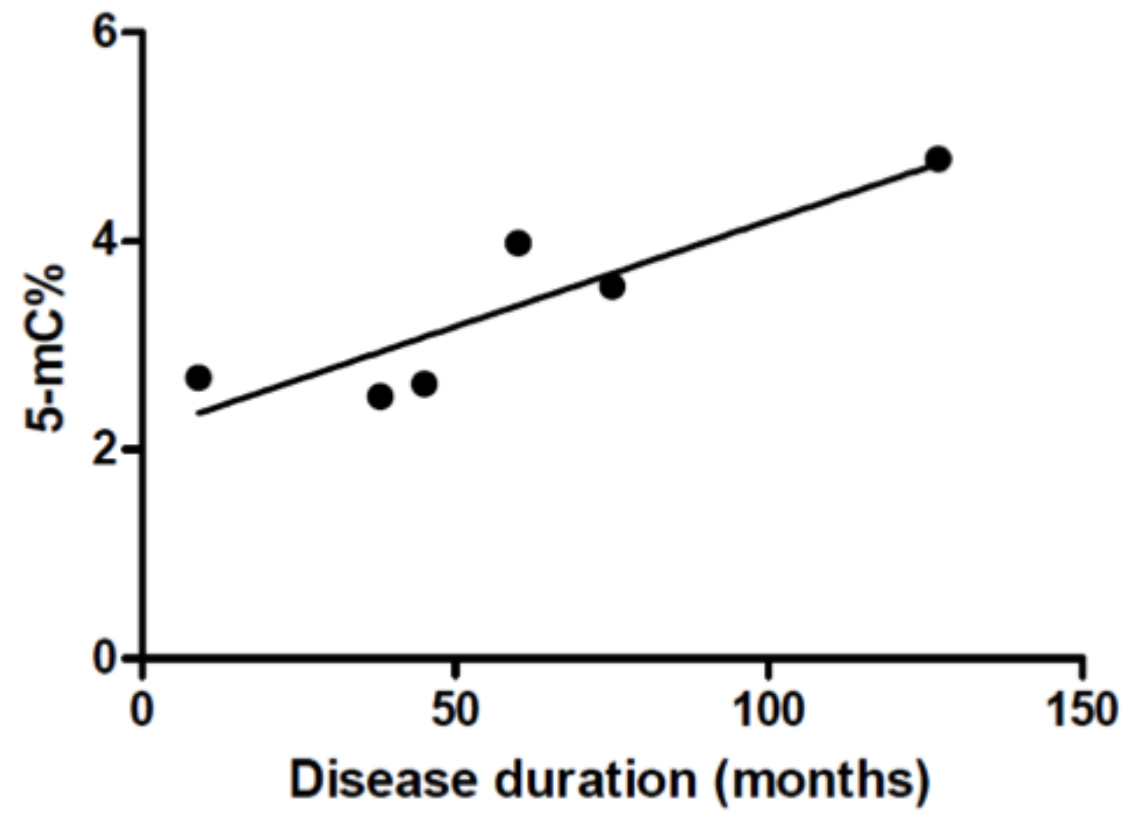

Figure 7 